\title{
Perspectivas Analítico-Comportamentais sobre a homossexualidade: análise da produção científica*
}

\section{Behavior Analytic Perspectives on Homosexuality: Analysis of the Scientific Publications}

\section{Perspectivas Analítico-Conductuales sobre la Homosexualidad: Análisis de la Producción Científica}

\section{Táhcita Medrado Mizael ${ }^{1}$}

[1] Universidade Federal de São Carlos I Título abreviado: Perspectivas Analítico-Comportamentais sobre a Homossexualidade | Endereço para correspondência: Laboratório de Estudos sobre o Comportamento Humano (LECH) - Edifício Carolina Bori, Universidade Federal de São Carlos, Rodovia Washington Luís, km 235 SP-310 - CEP 13565-905, São Carlos, São Paulo, Brasil I Email: tahcitammizael@gmail.com I DOI /10.18761/PAC.2017.011

Resumo: Pesquisadores como Skinner e Holland escreveram sobre as possibilidades de a análise do comportamento ser útil na superação de problemas sociais relevantes, como o racismo e o sexismo. Levando em consideração a relevância social do tema homossexualidade e a produção tecnológica e científica da análise do comportamento para o auxílio de indivíduos e/ou na análise de questões sociais relevantes, o objetivo deste trabalho foi analisar a produção científica da área sobre as questões ligadas à homossexualidade, ressaltando o que foi pesquisado, as possíveis contribuições da área, e as lacunas que poderão ser preenchidas em estudos futuros. As palavras-chave "homossexualidade", "orientação sexual", "heterossexualidade" e "bissexualidade" foram buscadas em 13 periódicos da área, nacionais e internacionais. Quatro artigos foram encontrados. De maneira geral, os artigos se propuseram a analisar a homossexualidade ou a homofobia/preconceito sexual a partir de contingências de reforçamento e punição às quais os indivíduos podem ter sido submetidos, ou analisar as possíveis "causas" biológicas da homossexualidade. Análises funcionais de comportamentos considerados preconceituosos e estudos sobre o uso de piadas e/ou outros comportamentos potencialmente discriminatórios como práticas reforçadas pela comunidade verbal são exemplos de lacunas da área que podem ser abordadas em pesquisas futuras.

Palavras-chave: homossexualidade, análise do comportamento, homofobia, preconceito sexual, práticas culturais. 
Abstract: Researchers such as Skinner and Holland have inquired about behavior analysis' utility in overcoming relevant social problems like racism and sexism. Considering the relevance of homosexuality as a social issue and the field's technological and scientific contributions for helping individuals and/or investigating relevant social phenomena, the aim of this study was to analyze behavior analysis scientific publications concerning issues related to homosexuality by pointing out what has been studied, the possible field's contributions and gaps that could be addressed in future inquiry. The key-words "homosexuality", "sexual orientation", "heterosexuality" and "bisexuality" were searched in 13 behavior-analytic journals from Brazil and abroad. Four articles were found. In general, these studies analyzed homosexuality or homophobia from the contingencies of reinforcement and punishment to which individuals may have contacted, or examined the possible biological "causes" of homosexuality. A functional analysis of prejudiced behaviors and studies examining the use of jokes and/or other possible prejudiced behaviors as practices reinforced by the verbal community are examples of gaps that could be addressed in future research.

Keywords: homosexuality, behavior analysis, homophobia, sexual prejudice, cultural practices.

Resumen: Investigadores como Skinner y Holland han indagado sobre la utilidad del análisis de la conducta en la superación de problemas sociales relevantes como el racismo y el sexismo. Teniendo en cuenta la homosexualidad como cuestión social y la producción tecnológica y científica del análisis de la conducta para el auxilio de individuos y/o en el análisis de cuestiones sociales relevantes, el objetivo de este estudio fue analizar la producción científica del área sobre cuestiones relacionadas con la homosexualidad, señalando lo que ha sido investigado, las posibles contribuciones del área, y las lagunas que se pueden abordarse en estudios futuros. Las palabras clave "homosexualidad", "orientación sexual", "heterosexualidad" y "bisexualidad" fueron buscadas en 13 periódicos del área, nacionales (de Brasil) e internacionales. Se han encontrado cuatro artículos. En general, estos estudios analizaran la homosexualidad o la homofobia/prejuicio sexual a partir de contingencias de reforzamiento y castigo a las cuales los individuos pueden haber sido sometidos, o examinaron las posibles "causas" biológicas de la homosexualidad. Un análisis funcional de las conductas prejuiciosas y estudios sobre el uso de chistes $y / u$ otras conductas posiblemente prejuiciosas como prácticas reforzadas por la comunidad verbal son ejemplos de lagunas del área que pueden abordarse en investigaciones futuras.

Palabras-clave: homosexualidad, análisis de la conducta, homofobia, prejuicio sexual, prácticas culturales.

*Táhcita M. Mizael é bolsista da Fundação de Amparo à Pesquisa do Estado de São Paulo (FAPESP, Processo No. 15/10225-5). A autora é afiliada ao Instituto Nacional de Ciência e Tecnologia sobre Comportamento, Cognição e Ensino (INCT-ECCE), apoiado pelo Conselho Nacional de Desenvolvimento Científico e Tecnológico (CNPq, Processo No. 573972/20087) e pela Fundação de Amparo à Pesquisa do Estado de São Paulo (FAPESP, Processo No. 2008/57705-8). A autora agradece a Aline Melina Vaz pela leitura atenta e comentários em uma versão prévia deste trabalho 
A homossexualidade foi e tem sido tema de diversos estudos, nas mais diversas áreas, com destaque para a biologia, as ciências sociais (especialmente antropologia e sociologia) e a psicologia. Com temas de pesquisas também bastante variados, que vão desde explicações da homossexualidade como um "terceiro sexo" (e.g., Nucci \& Russo, 2009), passando por explicações pautadas na biologia, como a correlação entre determinados genes e a expressão da homossexualidade (e.g., Bocklandt \& Hamer, 2003), até o entendimento da homossexualidade como variação sexual não-patológica e, inclusive, como algo de "origem social" e, que, portanto, não prescindiria de uma causa (e.g., Foucault, 1984; 1985; Weeks, 2000), este tema tem sido terreno fértil de pesquisas na área da sexualidade humana (mas não restrita a ela).

$\mathrm{Na}$ psicologia, muitos estudos investigaram, entre outras coisas, não só possíveis "causas" para este padrão comportamental/orientação como também relações entre a homossexualidade e transtornos psicológicos (e até a homossexualidade como um transtorno ou patologia em si - e.g., American Psychiatric Association, 1952; Bayer 1987, Friedman \& Downey 1998). Apesar de alguns pesquisadores, desde o final da década de 1950 já desafiarem a noção de que a homossexualidade seria uma patologia (e.g., Hooker, 1957), foi somente após o ano de 1973, quando a Associação Americana de Psiquiatria retirou a homossexualidade (chamada até então de "homossexualismo") da Classificação Internacional de Doenças, seguida pelo apoio a essa decisão pela Associação Americana de Psicologia, em 1975, que outros aspectos da homossexualidade, não mais considerada uma patologia, começaram a ser pesquisados com maior afinco, como as implicações do preconceito sexual, ou homofobia (preconceito dirigido a indivíduos cuja prática ou orientação sexual não é heterossexual, e/ou a indivíduos cuja expressão e/ou identidade de gênero não é coerente com o gênero que foi assignado no nascimento) na saúde mental de indivíduos cuja orientação ou prática sexual é homossexual (e.g., Herek \& Garnets, 2007).

A análise do comportamento, fundamentada no Behaviorismo Radical, propõe análises baseadas na história dos organismos (que podem ser humanos ou não), demonstrando como determinadas respostas tem suas probabilidades de ocorrência modificadas com base nas consequências dessas respostas. Além disso, em suas análises, os contextos nos quais as respostas ocorrem são também importantes, uma vez que eles possibilitam a emissão de certas respostas, sinalizando a disponibilidade de reforçadores, ou a ausência destes, assim como de consequências potencialmente aversivas (e.g., Carvalho Neto, 2002; Sério, 2005). Pensando na interface entre a análise do comportamento e "questões sociais", teóricos e pesquisadores como Skinner, Moore e Holland escreveram sobre as possibilidades de a análise do comportamento ser útil na superação de problemas sociais relevantes, como a má distribuição de renda, o racismo, a fome, o sexismo, entre outros (e.g., Holland, 1978; Moore, 2003; Skinner, 1953/1970; 1978, e também Guerin, 1992/2009; Holpert, 2004; Mattaini \& Thyer, 1960). Desse modo, pelo menos em tese, a análise do comportamento poderia contribuir no estudo de questões ligadas à homossexualidade, não enquanto uma "busca causal", mas principalmente no estudo do estabelecimento e manutenção da homofobia/ preconceito sexual, e na proposição de modelos experimentais de preconceito e/ou estigmatização, os quais poderiam ser utilizados em aplicações futuras que objetivem diminuir tais preconceitos, entre outras contribuições.

Levando em consideração, portanto, a relevância social do tema homossexualidade, e o fato de que a análise do comportamento é uma área que se dedica ao estudo do comportamento (aberto e encoberto), que sua produção já é bastante relevante no auxílio de vários indivíduos e/ou na análise de questões sociais relevantes (e.g., pessoas com problemas de aprendizagem - e.g., de Rose, de Souza, \& Hanna, 1996, aprendizagem de repertórios em indivíduos com transtorno do espectro autista e.g., Lovaas, 1987; Sallows \& Graupner, 2005, experimentos que diminuíram vieses raciais negativos em crianças - e.g., Mizael, de Almeida, Silveira, \& de Rose, 2016), o objetivo dessa pesquisa foi analisar a produção científica da análise do comportamento sobre questões ligadas à homossexualidade, ressaltando o que foi pesquisado, quais as possíveis contribuições para a área, e as lacunas que podem ser preenchidas em estudos futuros. 
Método

Foi realizada uma revisão bibliográfica em 13 periódicos de análise do comportamento, nacionais e internacionais. Os periódicos nacionais foram: Revista Brasileira de Análise do Comportamento (REBAC), Revista Brasileira de Terapia Comportamental e Cognitiva (RBTCC), e Revista Perspectivas em Análise do Comportamento. Os periódicos internacionais pesquisados foram: Acta Comportamentalia, Behavior and Social Issues, Behavior Analysis: Research and Practice, Journal of Applied Behavior Analysis (JABA), Journal of Contextual Behavioral Science, Journal of the Experimental Analysis of Behavior (JEAB), Revista Argentina de Ciencias del Comportamiento, The Analysis of Verbal Behavior, The Behavior Analyst, $\mathrm{e}$ The Psychological Record. A escolha por esses periódicos se deu por serem, de maneira geral, alguns dos periódicos mais conhecidos da área.

As palavras-chave utilizadas foram: "homossexualidade", "orientação sexual", "heterossexualidade" e "bissexualidade" e seus equivalentes em inglês ou espanhol. Não houve período de tempo estabelecido para a busca. O critério de inclusão dos artigos foi o tema da homossexualidade como algo central no artigo, de modo que foram excluídos artigos que abordavam a sexualidade de maneira geral (e.g., Roche \& Barnes-Holmes, 2002). A autora decidiu não buscar termos que explicitamente indicam a patologização da homossexualidade, como os termos "homossexualismo" e "bissexualismo", uma vez que um dos objetivos da pesquisa foi, justamente, analisar as possíveis contribuições da área no estudo das questões relacionadas à homossexualidade.

Como o número de pesquisas encontradas que se encaixavam no critério de inclusão foi baixo (três artigos), uma nova busca de artigos publicados foi feita na plataforma Scielo, em português, utilizando além de uma das palavras-chave supracitadas, o termo "análise do comportamento". Mais um artigo foi encontrado com base nessa busca.

\section{Resultados}

Quatro artigos foram encontrados. O primeiro, de autoria de Richard Malott (1996), foi publicado na revista Behavior and Social Issues. A pesquisa de Carvalho, da Silveira e Dittrich (2011) foi a única publicada em um periódico brasileiro de análise do comportamento (REBAC). O estudo de Barona e Aponte (2014) foi publicado na Revista Argentina de Ciencias del Comportamiento e o último artigo encontrado, publicado em 2015 e escrito por Fazzano e Gallo (2015), foi publicado em uma revista de psicologia não específica à análise do comportamento (Temas em Psicologia).

Malott (1996) propôs analisar a sexualidade, transexualidade, homossexualidade e heterossexualidade a partir de uma ótica analítico-comportamental. Assim, o papel da "natureza" e da "cultura" (nature e nurture, respectivamente) na determinação da orientação sexual foi analisado a partir de dois componentes: os papéis sexuais ${ }^{1}$ (sex-role; termo que costuma se referir às normas e/ou expectativas sociais de gênero nas sociedades, ou seja, à construção de masculinidades nos homens e feminilidades nas mulheres, de acordo com as normas societais) e estilo comportamental, e os valores sexuais. Defendendo as contingências e o resultado comportamental (behavioral outcome) em detrimento da forma ou topografia comportamentais, o autor afirma que os papéis sexuais e estilos comportamentais são aprendidos via contingências de reforçamento e punição.

Utilizando-se de exemplos em outras áreas, as quais mostram que aspectos antes considerados inatos são, na verdade, sujeitos às contingências de reforçamento (como ocorre no fenômeno de imprinting ${ }^{2}$ ) e também fazendo o uso de uma analo-

1 Tal termo foi bastante criticado (ver, por exemplo, Connell, 1987) e, atualmente, sugere-se, por exemplo, a utilização de "masculinidades/feminilidades" em vez de "papéis sexuais".

2 De acordo com Nunes, Fernandes e Vieira (2007), imprinting, ou estampagem, em português, é um "conceito empregado para definir o comportamento de filhotes de gansos exibidos como resultado da experiência precoce em fixar-se à imagem da primeira figura (geralmente a materna) com que entravam em contato, após eclodir dos ovos, e a tendência em manterem a proximidade com essa figura durante o seu estágio inicial de desenvolvimento" (p. 162). 
gia com a aprendizagem de uma língua estrangeira, Malott (1996) argumenta sobre como os processos de aprendizagem ocorrem de maneira tão constante, que torna difícil listá-los, ou considerá-los, de fato, aprendizagens, frente a um desempenho tão competente. Analisando separadamente os diferentes tipos de estimulação sexual, o autor comenta sobre a aprendizagem da aversividade condicionada, e relata que, para a maioria de nós, nossa aprendizagem sobre tipos de estimulação sexual aversiva ocorre não por pareamentos típicos dos estudos de processos básicos (e.g., luz + choque), mas por meio de relações verbais, como os comentários sobre "quão inapropriadas (imorais, repugnantes) são certas fontes de estimulação sexual” (p. 129).

Malott (1996) afirma acreditar, portanto, que nós nascemos bissexuais ou, inclusive, "multissexuais", ou seja, suscetíveis a reforçadores sexuais de variadas fontes, e que nossa inclinação em direção a determinado(s) sexo/gênero, assim como a aversão que sentimos frente a certas formas de estimulação sexual são resultado de nossa história comportamental. Diz o autor: "nós não temos conhecimento (to be unaware of) da programação social sutil, mas sempre presente, que nos força aos papéis sexuais que adquirimos" (p. 130). Apesar disso, Malott (1996) ressalta que, a despeito de a inclinação afetivo-sexual ser algo aprendido, isso não significa que seja algo que escolhemos como "qual chapéu vestir para ir ao supermercado" (p. 130). Assim, o autor diz que muitos comportamentos e valores aprendidos até determinada idade (como a fase da pré-escola) "interagem com as contingências de reforçamento e punição existentes, de modo a tornar quase impossível modificá-los quando nos tornamos adultos" (p. 130).

Em seguida, Mallot (1996) traz alguns argumentos baseados na biologia, para salientar o quanto as explicações pautadas em questões biológicas poderiam ser dadas também a partir da aprendizagem, e que correlações não são suficientes para definir a homossexualidade como algo genético, uma vez que aspectos ambientais, como o estresse podem, de fato, ocasionar mudanças cerebrais. Uma crítica ao modelo médico também é feita, e o autor comenta que este modelo pode ter influenciado pesquisadores a quererem buscar "genes homossexuais", mas não "genes heterossexuais".
O preconceito por parte dos pesquisadores que buscam uma base genética ou biológica para a homossexualidade também é ressaltado por Malott (1996), ao mostrar que essa busca se baseia em uma noção indevida de que a homossexualidade é uma coisa; essa coisa sendo uma doença. Afinal, não se busca uma causa genética para as preferências em oferecer ou receber estimulação anal, oral ou genital, então porque se busca um "gene homossexual" (e não heterossexual)?

Ao propor uma análise molecular do comportamento sexual, Malott (1996) sugere o abandono do uso de termos como homossexual, heterossexual e homossexualidade, de modo a analisar quais variáveis controlam os diferentes componentes dos comportamentos e papéis sexuais. Sua exposição é complementada pelo questionamento das análises de estímulos: o que são homens e mulheres? Como definí-los? O tamanho da variação em uma cultura, e entre diferentes culturas (e subculturas) é outro indicativo de como esses conceitos são aprendidos. Além disso, uma definição a partir da genitália de um indivíduo também não auxiliaria na análise, uma vez que "o comportamento sexual e os valores frequentemente se tornam bem estabelecidos bem antes do contato ou conhecimento rudimentar sobre a genitália do outro sexo" (p. 133).

Para finalizar, Malott (1996) discorre sobre a homofobia. Utilizando como exemplos as escrituras da Bíblia e a política americana “don't ask, don't tell" que proibia a participação de indivíduos abertamente homossexuais nas forças armadas americanas, o autor escreve que o argumento para condenar a homossexualidade seria a incapacidade de reprodução. Como algumas pessoas ficam sob controle dessas contingências de reforçamento associadas com reforçadores sexuais não reprodutivos, $\mathrm{e}$ dado que a disponibilidade desses vários reforçadores é grande, além de serem bastante poderosos, seus efeitos poderiam gerar, de fato, a diminuição das taxas de procriação de uma sociedade.

Desse modo, criam-se uma série de mecanismos que condenam atos que não levem à procriação, tais como a masturbação, o sexo "recreativo", o coito interrompido e o sexo anal. Afinal, "se nós fossemos biologicamente programados a (wired to) achar o sexo não reprodutivo (incluindo a estimulação sexual entre pessoas do mesmo gênero) aver- 
sivo ao invés de reforçador, não haveria necessidade de todas essas sanções legais e religiosas. Mas nós não somos" (Malott, 1996, p. 137). Assim, formas de estimulação sexual não reprodutivas são tornadas não-naturais, vergonhosas, sujas e desagradáveis graças a pareamentos com estímulos aversivos, como punições físicas, mas principalmente por meio de relações verbais, ou seja, sanções sociais, religiosas e legais.

Esses pareamentos e relações verbais, apesar de altamente efetivos, não funcionariam com todos os indivíduos, de modo que a não-efetividade desses "mecanismos", devido a diferenças nas histórias comportamentais dos indivíduos, levaria à manutenção do valor reforçador da estimulação sexual entre pessoas do mesmo gênero, e em alguns casos, ao estabelecimento de funções aversivas ao outro gênero, por relações diretas ou indiretas. Assim, é o controle aversivo que tornaria a estimulação sexual restrita, de modo que, a partir de uma intervenção comportamental intensa, seria possível reverter tais estimulações aversivas condicionadas. Malott (1996) finaliza seu artigo defendendo intervenções que ajudem indivíduos cuja orientação ou prática sexual é não-heterossexual com o uso de procedimentos que "modifiquem" seu comportamento sexual, ou que os ajudem a resistir às opressões sofridas.

De Carvalho et al. (2011) fizeram uma revisão dos estudos publicados no Journal of Applied Behavior Analysis (JABA) sobre a patologização ou não da homossexualidade utilizando os termos gay, LGB, LGBT, homosexual, homosexuality, homosexualism, bisexual, bisexuality, bisexualism, transexual, transexuality, transexualism, transvestism, transvestic, lesbianism, lesbian, sexuality, sex, gender, male e female. De 1968 até 2010 (data da busca), 10 artigos atenderam o critério de inclusão, ou seja, possuíram pelo menos uma dessas palavras-chave no título, além de o texto se tratar, de fato, da temática (não apenas marginalmente).

Dos dez trabalhos encontrados, metade patologizava a homossexualidade; dois deles não a trataram como um desvio, e nos três restantes não foi possível identificar se os autores a patologizavam. Com relação aos cinco últimos artigos, os dois trabalhos que não trataram a homossexualidade como desvio (Nordyke, Baer, Etzel, \& LeBlanc, 1977;
Winkler, 1997) não foram incluídos neste trabalho por serem réplicas de um trabalho anterior que tentou modificar a "orientação sexual" ou "papéis sexualmente desviantes" de uma criança (Rekers \& Lovaas, 1974); os três trabalhos restantes não foram incluídos pois sua inclusão na pesquisa de de Carvalho et al. (2011) ocorreu devido ao uso das palavras-chave "sexual" ou "sex", as quais não foram empregadas na presente pesquisa.

De acordo com de Carvalho et al., (2011), a maior parte das pesquisas foi publicada até o fim da década de 1970. Em dois trabalhos, houve uma tentativa explícita de alterar a orientação sexual ou papéis "sexualmente desviantes" (expressão de gênero não coerente com o sexo atribuído no nascimento), por meio do uso de procedimentos aversivos. Dois trabalhos constituíram comentários de um dos trabalhos de tentativa de modificação da orientação sexual, uma vez que o alvo da mudança era uma criança, e a demanda pelo tratamento vinha dos pais. Estes comentários argumentavam sobre o posicionamento adequado de analistas do comportamento quando uma demanda não vem da própria pessoa que recebe tratamento, além de questionar sobre a possibilidade de os "sintomas" (e.g., isolamento social, sofrimento) relatados serem resultado das práticas sociais, e não do fato de um indivíduo ser homossexual ou se comportar de acordo com um gênero diferente do que lhe foi assignado no nascimento.

A patologização da homossexualidade nesses periódicos revisados perdurou até 1979 , sendo, portanto, correlacionada (e provavelmente influenciada) pela retirada da homossexualidade da lista de doenças da Associação Americana de Psiquiatria, que ocorreu em 1973, e pelo pronunciamento da Associação Americana de Psicologia, apoiando tal decisão, em 1975. De Carvalho et al. (2011) ressaltaram a escassez de pesquisas sobre o tema sexualidade na área, uma vez que, em 42 anos, apenas sete artigos foram publicados (excetuando-se as réplicas ou tréplicas de trabalhos), o equivalente a um artigo a cada seis anos.

O trabalho de Barona e Aponte (2014) discorreu sobre a natureza multifatorial do comportamento homossexual, ou seja, sobre quais seriam as origens da homossexualidade/padrões de comportamento homossexual, elencando as principais des- 
cobertas que relacionam a homossexualidade com aspectos biológicos, tais como a genética, epigenética, atuação de hormônios, questões neurológicas e relacionadas à evolução. Com relação à influência genética, os autores discorrem sobre três hipóteses: a chamada seleção sexualmente antagonista, que seria um conjunto de genes que diminuiria o êxito em se reproduzir e gerar descendentes de indivíduos homossexuais, ao mesmo tempo em que aumentaria o êxito dos indivíduos heterossexuais (através de uma maior fertilidade, por exemplo), contrabalanceando, portanto, a aparente "desvantagem evolutiva" dos indivíduos homossexuais.

A segunda hipótese seria baseada nos efeitos pleiotrópicos, que indicam que os indivíduos portadores de "genes homossexuais" teriam um favorecimento da expressão de comportamentos vantajosos como o cuidado parental, a empatia e a sensibilidade. Nesse caso, esses genes seriam passados para quaisquer indivíduos, homossexuais ou não (inclusive por indivíduos homossexuais que se reproduziriam - veja que a prática sexual não precisa coincidir totalmente com o desejo sexual e.g., Louro, 2008), o que explicaria a persistência evolutiva da homossexualidade. A terceira e última hipótese explicaria parcialmente a homossexualidade a partir da metilação do DNA. Metilação é algo que influencia a expressão gênica, ao silenciar alguns genes. No caso da homossexualidade, Barona e Aponte (2014) apontam estudos que mostram que "mães de homens gays possuem padrões específicos de metilação no cromossomo X" (p. 63), o que não ocorre com mães de homens heterossexuais. Por ser possivelmente herdável, essa explicação sugere que existe uma maior predisposição da homossexualidade em descendentes de homossexuais, como sugerido por estudos feitos com irmãos gays.

Com relação à influência hormonal, a exposição a níveis de testosterona e estrogênio no pré-natal tem sido correlacionada com a expressão da homossexualidade em homens e mulheres. Entretanto, os estudos relatados por Barona e Aponte (2014) têm mostrado inconsistências, uma vez que resultados opostos (com relação à exposição desses hormônios e a expressão da homossexualidade) foram encontrados em diferentes pesquisas. A neurobiologia tem sugerido diferenças entre os cérebros de indivíduos homo e heterossexuais, apontando diferenças de tamanho em estruturas como o núcleo supraquiasmático do hipotálamo como parcialmente responsáveis pelo comportamento homossexual. Entretanto, os autores salientam que a atuação de hormônios no pré-natal pode influenciar no tamanho das estruturas cerebrais, o que aponta para uma ação conjunta entre hormônios e aspectos neuroanatômicos.

A ordem de nascimento dos filhos homens também é descrita, sendo correlacionada com a homossexualidade. Barona e Aponte (2014) descrevem estudos mostrando que é mais provável que um homem seja homossexual se tiver vários irmãos (do sexo masculino) mais velhos. A explicação para isso seria a mudança no sistema imune das mães a cada gestação, onde a produção de determinados anticorpos correlacionados com a masculinização do cérebro não funcionaria de maneira adequada. Entretanto, o chamado "efeito do irmão mais velho" seria responsável por apenas $14 \%$ da homossexualidade nos homens.

Por fim, argumentando sobre as causas últimas do comportamento homossexual, a seleção interdêmica seria uma hipótese para a origem e persistência do comportamento homossexual. Este tipo de seleção está relacionado, de acordo com os autores, com a vida social e com a cooperação. Desse modo, a existência de indivíduos homossexuais levaria a uma sociedade com disponibilidade de recursos (não é explicitado como, a partir da cooperação, haveria uma maior disponibilidade de recursos), o que seria útil na manutenção da vida. Essa maior capacidade de cooperação, aliada ao fato de que alguns indivíduos homossexuais também se reproduziriam, explicaria a persistência da homossexualidade ao longo dos anos. O artigo conclui, enfim, que a homossexualidade requereria não uma, mas múltiplas explicações biológicas sobre sua origem, uma vez que seria algo multifatorial, apesar de falar brevemente sobre a importância de somar às explicações biológicas as "forças sociais" que influem sobre a manutenção do padrão de comportamento homossexual/homossexualidade.

No trabalho mais recente encontrado, Fazzano e Gallo (2015) analisaram o fenômeno da homofobia utilizando-se do conceito de controle aversivo, descrevendo-o sob o ponto de vista do agressor e da vítima. Os autores ressaltam a escassez de estudos 
sobre as causas da homofobia, e comentam sobre a pouca utilidade de estudos que apontem causas "mentalistas" para o fenômeno, que explicam a homofobia a partir de teorias psicodinâmicas que não auxiliariam no combate a esse tipo de violência, por atribuir as causas desses ataques "a uma entidade ontológica, a qual é inacessível e imutável” (p. 537). Essa desconsideração do contexto tem implicações sérias e negativas, uma vez que ela poderia retirar a responsabilidade por esses atos hediondos de agências de controle como o governo. Assim, os autores defendem a utilidade de uma compreensão analítico-comportamental do fenômeno.

Definindo a homofobia como "um conjunto de comportamentos complexos, envolvendo comportamentos operantes e respostas emocionais, relativos às várias modalidades de agressão (seja física, psicológica ou sexual) contra indivíduos homossexuais ou que se identifiquem com a cultura homossexual" (p. 538), Fazzano e Gallo (2015) propõem o estabelecimento de hipóteses funcionais para a ocorrência deste fenômeno. A presença de um indivíduo homossexual (ou percebido como tal) constituiria, portanto, uma operação motivadora para a atuação do agressor. Este indivíduo seria, portanto, um estímulo aversivo para o agressor, o qual se vale da agressão para retirar ou diminuir o estímulo aversivo. Desse modo, o episódio de agressão seria reforçado negativamente.

O indivíduo homossexual passaria a ser considerado um estímulo aversivo para o agressor a partir de processos de aprendizagem, ou seja, da modelagem, do controle por regras e/ou da modelação, e a persistência ou manutenção do comportamento de agressão ocorreria a partir da retirada do estímulo aversivo, ou seja, do indivíduo identificado como homossexual.

Do ponto de vista do agressor, seria ainda possível que ele fosse punido à longo prazo, como, por exemplo, via processos penais e/ou prisão. Entretanto, uma vez que o comportamento é mais sensível às consequências imediatas, em comparação com as consequências à longo prazo, há uma menor probabilidade de que o comportamento de agressão seja influenciado à partir dessas consequências negativas e, levando em consideração que, na sociedade brasileira, não há uma legislação que criminalize a homofobia (apesar de os dados mais recentes indicarem o assassinato de um LGBT - lésbicas, gays, bissexuais, travestis e transexuais - a cada 25 horas no Brasil; Grupo Gay da Bahia, 2016), é bastante provável que o agressor não entre em contato com essas consequências potencialmente aversivas, o que diminui ainda mais a probabilidade de que este comportamento seja reduzido (em frequência e/ou magnitude).

Com relação à perspectiva da vítima, o agressor a puniria, ocasionando a cessação do comportamento percebido como indicativo de homossexualidade (e.g., dois homens se abraçando), pelo menos momentaneamente. Os efeitos da punição frequentemente não se mantêm ao longo do tempo, mas outras variáveis (como a intensidade da agressão) podem modular seus efeitos, fazendo com que, no exemplo do abraço, "os dois homens não voltem a se abraçar no mesmo local (onde ocorreu a agressão), ou em contextos parecidos, ou na presença de pessoas com alguma característica que lembre o agressor, ou, simplesmente, não abraçam mais" (Fazzano \& Gallo, 2015, p. 541, parênteses adicionados). Essas dicas contextuais se relacionam também com os efeitos colaterais da punição, ou seja, ao fato de que pode ocorrer um condicionamento, de modo que determinado contexto possa sinalizar uma maior probabilidade de punição, a partir de um histórico de punição prévia. Essa transferência da aversividade para estímulos previamente neutros é preocupante, pois pode levar ao isolamento social, para citar apenas um dos efeitos da homofobia em suas vítimas.

Outra resposta que pode ocorrer com o uso de punição é a emissão de respostas incompatíveis com a resposta punida. Desse modo, Fazzano e Gallo (2015) argumentam que evitar sair, evitar relacionamentos e, inclusive, "ficar no armário" (não assumir sua orientação sexual publicamente) podem ser considerados exemplos de respostas incompatíveis com a punição, que podem surgir em situações em que determinada resposta foi punida, evitando, portanto, um novo contato com a estimulação aversiva advinda da agressão. Por fim, os autores levantam também a possibilidade de que as respostas que ocorrerem após a punição não sejam simplesmente incompatíveis, mas opostas às respostas previamente punidas. Nesse caso, se engajar em comportamentos heterossexuais, decidir ser ce- 
libatário, e inclusive passar a agredir outros homossexuais também seriam respostas possíveis, diante de um histórico de punição de comportamentos considerados homossexuais.

$\mathrm{O}$ artigo finaliza discorrendo sobre a importância da adoção de políticas públicas de combate à homofobia que atuem em médio e longo prazo, ressaltando que a importância de entender as causas da homofobia se relacionam com a formulação de metodologias de combate às agressões, e evidenciando os efeitos da omissão deste fenômeno na ciência: "deixar o fenômeno da homofobia ao relento, sem preocupar-se cientificamente com o mesmo, é reafirmar o preconceito em suas diferentes formas" (Fazanno \& Gallo, 2015, p. 544).

\section{Discussão}

O objetivo dessa pesquisa foi revisar a produção científica analítico-comportamental sobre questões relacionadas à homossexualidade. Além de identificar uma pequena quantidade de artigos publicados, nas quatro pesquisas revisadas não houve a menção da homossexualidade como patologia, pelo menos de maneira explícita, o que pode ser considerado um reflexo das mudanças ocorridas em órgãos normativos da psiquiatria e psicologia americanas e brasileiras (e.g., Associação Americana de Psicologia, Associação Americana de Psiquiatria, Conselho Federal de Medicina, Conselho Federal de Psicologia, Organização Mundial da Saúde), as quais retiraram a homossexualidade do rol de doenças listadas em seus manuais (Classificação Internacional de Doenças e Manual Diagnóstico e Estatístico de Transtornos Mentais) entre os anos de 1973 e 1985. Entretanto, o trabalho de Barona e Aponte (2014), o qual objetivou destacar algumas das possíveis causas da homossexualidade, pode ser considerado, em última instância, como um trabalho que patologiza as homossexualidades, uma vez que sua busca se restringe às origens da homo, mas não da heterossexualidade.

A pesquisa de Malott (1996), embora explicite a não-patologização de nenhuma orientação sexual, ou identidades trans, sugere que o comportamento sexual pode ser modificado após uma intervenção comportamental intensiva, e que as duas alternativas em termos de tratamento psicológico de um indivíduo cuja prática e/ou orientação sexual não é heterossexual seriam a aceitação e aprendizagem de formas de resistir às opressões sofridas, ou o tratamento de indivíduos homossexuais a partir de intervenções comportamentais focadas na mudança da orientação sexual do indivíduo. No ano de 2009, foi publicada pela Associação Americana de Psicologia um estudo de revisão sobre as terapias chamadas "esforços de mudança da orientação sexual" (sexual orientation change efforts - SOCE), que analisava as pesquisas publicadas entre os anos de 1960 e 2007, buscando verificar, principalmente, a eficácia e segurança desse tipo de terapia. Os resultados mostraram que raramente havia manutenção das mudanças alegadas (e.g., passar a desejar sexualmente um indivíduo de sexo diferente do seu), pouquíssimos pacientes tiveram, de fato, uma redução na atração sexual sentida por alguém do mesmo sexo (geralmente, ocorria diminuição da atração, porém para todos os estímulos possivelmente sexuais), de modo que a diminuição de comportamentos sexuais entre indivíduos do mesmo sexo, e aumento destes comportamentos entre indivíduos de sexo diferente foi rara. Com relação à segurança, algumas reações adversas da terapia incluem depressão, ideação suicida, perda da atração sexual geral, impotência e transtornos de ansiedade. Um grande número de indivíduos desistia do tratamento, pautado, muitas vezes, em condicionamento aversivo, devido potencialmente a estes efeitos colaterais.

Concluiu-se, portanto, que através desse tipo de terapia é "improvável que os indivíduos se tornem capazes de reduzir a atração pelo mesmo sexo ou ter maior atração sexual pelo outro sexo" (APA, 2009, p. 83). Além disso, os únicos benefícios possíveis advindos dessas terapias de modificação da orientação sexual seriam aqueles relacionados com o suporte social e com a diminuição do isolamento social, uma vez que os pacientes encontravam outros indivíduos com conflitos semelhantes. Para complementar, a APA deixou explícito que a atração, o comportamento sexual e a orientação voltada ao mesmo sexo são variantes positivos e normais da sexualidade humana, e que nenhum estudo empírico ou revisado por pares encontrou resultados 
que apoiem teorias que relacionam a orientação homossexual a traumas ou disfunções familiares (APA, 2009).

É importante reiterar, ainda, que os psicólogos brasileiros não podem oferecer qualquer tipo de terapia que proponha uma "cura" ou modificação da orientação ou prática sexual, incluindo aqui métodos coercitivos que levem indivíduos homossexuais e/ou aqueles cuja prática sexual é não-heterossexual a tratamentos que não foram solicitados. Os psicólogos também não podem colaborar com qualquer tipo de serviço ou evento que proponha algum tipo de tratamento ou "cura" para as homossexualidades (Brasil, 1999). Isso não significa que ao psicólogo é vedado tratar homossexuais. Como diz Vieira, Hernández e Uziel (2013):

Ora, qualquer psicóloga/o, minimamente bem formado e informado, sabe que a Resolução ${ }^{\circ}$ 1/1999 do Conselho Federal de Psicologia não restringe ou proíbe que a/o profissional acolha, seja nos consultórios, seja nos equipamentos de saúde, o sofrimento de qualquer pessoa por sua prática sexual. Dito de outro modo, não se trata, obviamente, de negar atendimento psicológico para alguém que expressa uma demanda de mudança na sua orientação sexual, mas, efetivamente, não significa oferecer intervenções "curativas" de caráter moralista e coercitivo de cunho religioso, tal como proposto pela Terapia de Reversão ou Reorientação Sexual (p. 140141).

Isso significa que a terapia, nesse contexto, deve ser voltada à aceitação, ao entendimento da homofobia como uma prática social bastante reforçada em diversos contextos e culturas, e ao desenvolvimento de formas de superação das opressões sofridas, entre outras ações. Outro aspecto importante identificado especialmente em algumas das pesquisas que foram revisadas por de Carvalho et al. (2001) foi a confusão entre os conceitos de orientação sexual e identidade ou expressão de gênero, como assumir que um indivíduo seja homossexual com base nos trejeitos (forma de andar, de falar, de se vestir, etc.). Orientação sexual pode ser definida como a inclinação afetivo-sexual que uma pessoa tem dirigida a alguém do mesmo sexo, de sexo diferente do seu ou de ambos os sexos (entre outras variações). Identidade de gênero, por sua vez, se refere a como um indivíduo se sente, se vê, ou se identifica, dentro das concepções existentes de gênero, independentemente do sexo assignado no nascimento. Um indivíduo pode ser, portanto, cisgênero (quando o sexo assignado no nascimento concorda com a identidade de gênero do indivíduo) ou transgênero (quando não há coerência entre identidade de gênero e sexo atribuído no nascimento). Por fim, a expressão de gênero denota a forma como a identidade de gênero pode ser expressa (ou não) a partir das roupas, acessórios, gestos e outros comportamentos. Desse modo, um indivíduo pode possuir uma identidade de gênero distinta de seu sexo assignado no nascimento, mas não a expressar, por ter sido punido no passado, ou apenas ter visto/lido sobre as punições que são dadas àqueles que não se conformam à suposta coerência entre sexo assignado no nascimento e identidade de gênero.

\section{Lacunas e Sugestões para Pesquisas Futuras}

Com base na baixa quantidade de artigos encontrados, muitas possibilidades de pesquisa podem ser apontadas. Algumas sugestões seguem:

- Analisar as implicações do preconceito sexual/homofobia sobre os indivíduos cuja orientação ou prática sexual não é heterossexual: o trabalho de Fazzano e Gallo (2015) é um exemplo disso, ao propor uma análise da seleção e manutenção de comportamentos "homofóbicos" a partir do ponto de vista do agressor e da vítima. Entretanto, essa é uma maneira de olhar para o fenômeno, o que permite outros tipos de análises, principalmente pautadas nas práticas sociais (e.g. metacontingências e macrocontingências) que têm mantido esses comportamentos de agressão (físicas e verbais) reportados diariamente;

- Analisar funcionalmente os diferentes tipos de discriminação, ou de comportamentos que podem ser considerados preconceituosos, especialmente aqueles que são considerados, em 
muitos contextos, como "brincadeiras" (e.g., piadas), analisando funcionalmente suas emissões e, assim, pensando em propostas interventivas mais diretivas e, inclusive distintas, dependendo das funções de tais comportamentos homofóbicos (e.g., Guerin, 2005 realizou uma análise contextual de comportamentos relacionados com o racismo, mostrando diversos contextos nos quais funções diferentes de "ser racista" [ser aceito, aumentar o status de seu próprio grupo, evitação, uso impensado de estereótipos, etc.] controlariam os comportamentos dos indivíduos);

- Analisar as concepções de terapeutas comportamentais sobre a homossexualidade (e outras sexualidades e gêneros dissidentes), tentando estabelecer hipóteses funcionais para seus posicionamentos (e.g., correlações entre a não-aprendizagem do assunto e a patologização das homossexualidades), o que poderia auxiliar em intervenções educativas voltadas ao esclarecimento de assuntos como a construção do gênero, do sexo e da sexualidade;

- Contribuir na diminuição dos essencialismos presentes em algumas concepções da homofobia como uma entidade que estaria dentro do indivíduo (homofóbico), sendo, portanto, algo tanto inacessível quanto imutável (Fazzano \& Gallo, 2015; Guerin, 2005; Moore, 2003) e evidenciando o papel do ambiente no estabelecimento e manutenção desse tipo de comportamento;

- Mostrar como o preconceito sexual/homofobia pode ser estabelecido a partir de relações verbais indiretas, formadas por equivalência ou outros tipos de relações (hierarquia, oposição, etc.) e evocadas quando da transferência e transformação de funções (por exemplo, quando criança, um menino pode aprender que "viado" é algo ruim, mesmo sem saber um significado para essa palavra. Quando ele cresce, aprende que viado é equivalente a "gay" e/ou "homossexual". Desse modo, os atributos negativos de viado podem ser compartilhados/transferidos para indivíduos que se definem ou que são percebidos como gays/ homossexuais), utilizando modelos teóricos e experimentais;
- Utilizar o paradigma de equivalência de estímulos ou a teoria das molduras relacionais na tentativa de diminuir vieses sexuais negativos. Mizael e colaboradores (2016), por exemplo, recrutaram crianças com 8 a 10 anos de idade que demonstraram vieses raciais negativos para fotos de pessoas negras, e as treinaram a relacionar, indiretamente, tais fotos com atributos considerados positivos, diminuindo, portanto, os níveis de viés racial obtidos antes da pesquisa (a avaliação das fotos de pessoas brancas e negras foram consideradas positivas após a fase de treino e de testes) e obtendo resultados importantes no estudo de procedimentos que podem levar à intervenções que poderão ser utilizadas no futuro. Além disso, este paradigma também poderia ser utilizado para diminuir o que tem sido chamado de "preconceito sexual ou homofobia internalizada" (e.g., Nunan, 2010), ou seja, uma atitude negativa direcionada a práticas, desejos e orientações sexuais não-heterossexuais em indivíduos cujo desejo, prática ou orientação sexual é, de fato, não-heterossexual;

- Valer-se dos conhecimentos de outras áreas que têm produção extensa sobre o tema, como as ciências sociais, na elaboração de trabalhos teóricos e empíricos, complementando-os e/ou contrastando-os com os pressupostos analítico-comportamentais.

$\mathrm{Na}$ análise do comportamento, consideram-se três níveis de seleção: a filogenética, a ontogenética, e a cultural. Enquanto no trabalho de Malott (1996) ressaltou-se quase que inteiramente apenas o segundo nível de seleção, o artigo de Barone e Aponte (2014) trabalhou sumariamente com o primeiro nível. A pesquisa de Fazzano e Gallo (2015), embora também ressalte aspectos importantes em uma análise ontogenética das origens, manutenção e (dificuldade na) diminuição da homofobia, relata conceitos que poderiam, no futuro, ser aprofundados em uma análise sobre a homofobia e o terceiro nível de seleção.

A presente pesquisa possui diversas limitações, como a seleção somente de artigos publicados em periódicos de análise do comportamento, ou que apontem no título do texto a análise do comportamento como forma de análise (excluindo, por- 
tanto, capítulos de livros, teses e dissertações), o fato de não incluir nas palavras-chave buscadas termos que patologizem a homossexualidade, e o foco em apenas uma das orientações/práticas sexuais. Entretanto, dado o número limitado de pesquisas feitas na área que se relacionem à diversidade sexual e de gênero, espera-se que este trabalho sirva como uma guia ou auxílio para a proposição de novas perguntas de pesquisa, que levem, especialmente, à identificação de práticas culturais que mantém comportamentos "homofóbicos" e/ou que auxiliam no estabelecimento e manutenção de preconceitos sexuais, com o intuito de planejar intervenções futuras que diminuam este e outros tipos de preconceitos presentes em nossa sociedade. Mais do que apontar os "pontos-fracos" das pesquisas revisadas, o foco deste trabalho foi o de verificar o que tem sido estudado, para que, assim, novos caminhos possam ser traçados, sempre priorizando a ética profissional e o respeito aos direitos humanos.

\section{Referências}

American Psychiatric Association (1952). Mental Disorders: Diagnostic and Statistical Manual. Washington, DC: American Psychiatric Association.

American Psychological Association (2009). Report of the task force on appropriate therapeutic responses to sexual orientation. Washington, DC: American Psychological Association.

Barona, D., \& Aponte, H. (2014). La naturaleza multifactorial del comportamiento homosexual humano: Una breve revisión. Revista Argentina de Ciencias del Comportamiento, 6(3), 61-70.

Bayer, R. (1987). Homosexuality and American Psychiatry: The Politics of Diagnosis. Princeton, NJ: Princeton University Press.

Bocklandt, S., \& Hamer, D. H. (2003). Beyond hormones: A novel hypothesis for the biological basis of male sexual orientation. Journal of Endocrinological Investigation, 26 (Suppl. 3), 8-12.

Brasil. Conselho Federal de Psicologia (1999). Resolução $n^{\circ}$. 1, de 22 de março de 1999. Estabelece normas de atuação para os psicólogos em relação à questão da orientação sexual.
Recuperado de: http://site.cfp.org.br/wp-content/uploads/1999/03/resolucao1999_1.pdf

Carvalho Neto, M. B. (2002). Análise do comportamento: Behaviorismo radical, análise experimental do comportamento e análise aplicada do comportamento. Interação em Psicologia, 6(1), 13-18. doi: 10.5380/psi.v6i1.3188

Connell, R. W. (1987). Gender and power: Society, the person, and sexual politics. Stanford University Press.

de Carvalho, M. R. A., da Silveira, J. M., \& Dittrich, A. (2011). Tratamento dado ao tema "homossexualidade" em artigos do Journal of Applied Behavior Analysis: Uma revisão crítica. Revista Brasileira de Análise do Comportamento, 7, 7281. doi: 10.18542/rebac.v7i2.1451

de Rose, J. C., de Souza, D. G., \& Hanna, E. S. (1996). Teaching reading and spelling: Exclusion and stimulus equivalence. Journal of Applied Behavior Analysis, 29, 451 469. doi: 10.1901/jaba.1996.29-451

Fazzano, L. H., \& Gallo, A. E. (2015). Uma análise da homofobia sob a perspectiva da análise do comportamento. Temas em Psicologia, 23(3), 535-345. doi: 10.9788/TP2015.3-02

Foucault, M. (1984). História da sexualidade: O uso dos prazeres. Vol 2. Rio de Janeiro: Graal.

Foucault, M. (1985). História da sexualidade: A vontade de saber. Vol.1. 8 ed. Rio de Janeiro: Graal.

Friedman, R. C., \& Downey, J. I. (1998). Psychoanalysis and the model of homosexuality as psychopathology: A historical overview. American Journal of Psychoanalysis, 58, 249-70. doi: 10.1023/A:1022583223820

Grupo Gay da Bahia (2016). Relatório de Assassinatos de LGBTs no Brasil no ano de 2016. Recuperado de: https://homofobiamata.files. wordpress.com/2017/01/relatc3b3rio-2016-ps. pdf

Guerin, B. (2005). Combating everyday racial discrimination without assuming racists or racism: New intervention ideas from a contextual analysis. Behavior and Social Issues, 14, 46-70.

Guerin, B. (2009). Análise do comportamento e a construção social do conhecimento [Behavior analysis and the social construction of knowledge]. Revista Brasileira de Análise do 
Comportamento, 5(1), 117-137. (Original publicado em 1992).

Herek, G. M., \& Garnets, L. D. (2007). Sexual orientation and mental health. Annual Review of Clinical Psychology, 3, 353-375. doi: 10.1146/ annurev.clinpsy.3.022806.091510

Holland, J. (1978). Behaviorism, part of the problem or part of the solution? Journal of Applied Behavior Analysis, 11, 163-174.

Holpert, E. C. (2004). Questões sociais na análise do comportamento: Artigos do Behavior and Social Issues (1991-2000). Revista Brasileira de Terapia Comportamental e Cognitiva, 11(1), 1-16.

Hooker, E. (1957). The adjustment of the male overt homosexual. Journal of Projective Techniques, 21(1), 18-31. doi: 10.1080/08853126.1957.10380742

Louro, G. L. (2008). Um corpo estranho: Ensaios sobre sexualidade e teoria queer. $1^{\text {a }}$. Ed. Belo Horizonte: Autêntica.

Lovaas, O. I. (1987). Behavioral treatment and normal educational and intellectual functioning in young autistic children. Journal of Consulting and Clinical Psychology, 55, 3-9. doi: 10.1037/0022-006X.55.1.3

Malott, R. W. (1996). A behavior-analytic view of sexuality, transsexuality, homosexuality, and heterosexuality. Behavior and Social Issues, 6(2), 127-140. doi: 10.5210/bsi.v6i2.288

Mattaini, M. A., \& Thyer, B. A. (Eds.). (1996). Finding solutions to social problems: Behavioral strategies for change. Washington, DC: American Psychological Association.

Mizael, T. M., de Almeida, J. H., Silveira, C. C., \& de Rose, J. C. (2016). Changing racial bias by transfer of functions in equivalence classes. The Psychological Record, 66, 451-462. doi: 10.1007/ s40732-016-0185-0

Moore, J. (2003). Behavior analysis, mentalism, and the path to social justice. The Behavior Analyst, 26(2), 181-193.

Nordyke, N., Baer, D. M, Etzel, B., \& LeBlanc, J. M. (1977). Implications of stereotyping and modification in sex role. Journal of Applied Behavior Analysis, 10, 553-557. doi: 10.1901/ jaba.1977.10-553
Nucci, M. F., \& Russo, J. A. (2009). O terceiro sexo revisitado: A homossexualidade no Archives of Sexual Behavior. Physis - Revista de Saúde Coletiva, 19(1), 127-147. doi: 10.1590/S010373312009000100007

Nunan, A. (2010). Preconceito internalizado e comportamento sexual de risco em homossexuais masculinos. Psicologia Argumento, 28(62), 247259.

Nunes, S. A. N., Fernandes, M. G., \& Vieira, M. L. (2007). Interações sociais precoces: Uma análise das mudanças nas funções parentais. Revista Brasileira de Crescimento e Desenvolvimento Humano, 17(3), 160-171. doi: 10.7322/ jhgd.19858

Rekers, G. A., \& Lovaas, O. I. (1974). Behavioral treatment of deviant sex-role behaviors in a male child. Journal of Applied Behavior Analysis, 7, 173-190. 10.1901/jaba.1974.7-173

Roche, B., \& Barnes-Holmes, D. (2002). Human sexual arousal: A modern behavioral approach. The Behavior Analyst Today, 3(2), 145-153.

Sallows, G. O. \& Graupner, T. D. (2005). Intensive behavioral treatment for children with autism: Four-year outcome and predictors. American Journal on Mental Retardation, 6, 417-438. doi: 10.1352/0895-8017(2005)110[417:IBTFCW]2. $0 . \mathrm{CO} ; 2$

Sério, T. M. A. P. (2005). O behaviorismo radical e a psicologia como ciência. Revista Brasileira de Terapia Comportamental e Cognitiva, 7(2), 247-261.

Skinner, B. F. (1970). Ciência e comportamento humano. Brasília: Ed. UnB/ FUNBEC. (Original publicado em 1953).

Skinner, B. F. (1978). Reflections on behaviorism and society. Englewood Cliffs: Prentice-Hall.

Vieira, L. F., Hernández, J. G., \& Uziel, A. P. (2013). As psicólogas e a homossexualidade: Noções, princípios e exercício profissional. In: L. A. Lhullier (Ed.). Psicologia: Uma profissão de muitas e diferentes mulheres (pp.121-148). Brasília: CFP.

Weeks, J. (2000). O corpo e a sexualidade. In: Louro, G. L. (Org.). O corpo educado: Pedagogias da sexualidade (pp. 35-82). Belo Horizonte: Autêntica. 
Winkler, R. C. (1977). What types of sex-role behavior should behavior modifiers promote? Journal of Applied Behavior Analysis, 10, 549552. doi: 10.1901/jaba.1977.10-549

\section{Informações do Artigo}

Histórico do artigo:

Submetido em: 08/07/2017

Primeira decisão editorial: 16/01/2018

Aceito em: 17/01/2018

Editor: Nicodemos B. Borges 